Lewis, S. L. (1998). Aetiology of transient global amnesia. Lancet; 352, 397-399.

Quinette, P. et al. (2006). What does transient global amnesia really mean? Review of the literature and thorough study of 142 cases. Brain; 129, 1640-1658.

Chiara Agosti, Barbara Borroni, Nabil AkKawi and

Alessandro Padovani

Department of Neurological Sciences, University of Brescia, Italy

Email: chiarett@libero.it

doi:10.1017/S1041610207005613

\title{
The influence of exclusion criteria on the relationship between suicide rates and age in cross-national studies
}

Traditionally, suicide rates increase with aging in many countries (Shah and De, 1998). However, exceptions to this observation are emerging. Data from the World Health Organization (WHO) in 1995 revealed that female suicide rates did not increase with age in Mauritius, Colombia, Albania and Finland (Shah and De, 1998). Suicide rates increased with age in Switzerland (AjdacicGross et al., 2006), Brazil (Mello-Santos et al., 2005) and China (Yip et al., 2000), but there were smaller peaks in the younger age-bands. Suicide rates among Australian, New Zealand and white American males increased with age, but suicide rates for females initially increased with age, peaking at menopause, and declining thereafter (Skegg and Cox, 1991; Woodbury et al., 1988; Snowdon and Snowdon, 1995). Suicide rates among non-white Americans (Seiden, 1981; Woodbury et al., 1988), Indians (Adityanjee, 1986; Bhatia et al., 1987), Jordanians (Daradekh, 1989), Indian immigrants to the U.K. (Raleigh et al., 1990; Needleman et al., 1997) and some east European countries (Sartorius, 1995) declined with increasing age.

With the emergence of studies from several countries without an increase in the suicide rate with aging, a recent cross-national study examined the relationship between suicide rates and age by obtaining data on suicide rates for males and females in seven age-bands - 16-24 years, 25-34 years, 35-44 years, 4-54 years, 55-64 years, 65-74 years and 75+ years - from the WHO website (www.3.who.int/whosis/mort/table1.cfm) for 62 countries (Shah, 2007). The main findings were: (i) a significant increase in suicide rates with increasing age in males and females in 25 and 27 countries respectively, and in both sexes in 17 countries; (ii) no significant increase in suicide rates with increasing age in males and females in 31 and 29 countries respectively, and in both sexes in 21 countries; (iii) suicide rates for all the age-bands were low in both sexes or females in countries without a significant increase in the suicide rate with increasing age in both sexes or in females only respectively; (iv) suicide rates were the highest in the younger age-bands in countries without a significant increase in male suicides rates with increasing age; (v) regional clustering was observed for countries without a significant increase in suicide rates with increasing age 
in both sexes (central and south American countries, and eastern European countries and countries emerging from the former Soviet Union), females only (south America) and males only (eastern European countries); and (vi) in a small number of countries, suicide rates declined with increasing age. The reviewers had advised the following exclusions: (i) age-bands of less than 1 year, 1-4 years and 4-15 years because suicide rates in these age-bands were very low (often zero); and (ii) those countries with small population sizes and with suicide rates of zero across all age-bands because data for an individual year may have missed cases of suicide.

With the passage of time and upon reflection, I wish to share what the results may have been if the data were analysed without these exclusions for reasons discussed below. The original unpublished analysis included suicide rates for males and females in the ten age-bands of less than 1 year, 1-4 years, 4-15 years, 16-24 years, 25-34 years, 35-44 years, 45-54 years, 55-64 years, 65-74 years and $75+$ years and included countries where the suicide rates in all the agebands was zero. The methodology for ascertaining the relationship between suicide rates and age was similar to that used in the published study (Shah, 2007), and included 81 countries. The main findings were: (i) a significant increase in the suicide rate with increasing age in males and females in 59 and 52 countries respectively, and in both sexes in 46 countries; (ii) no significant increase in the suicide rate with increasing age in males and females in 22 and 29 countries respectively, and in both sexes in 16 countries; (iii) suicide rates for all the age-bands were low in both sexes or females in countries without a significant increase in the suicide rate with increasing age in both sexes or in females only respectively; (iv) in countries without a significant increase in the suicides rate with increasing age in males only, there were peaks with the highest suicide rate in the younger age-bands; and (v) regional clustering was observed for countries without a significant increase in the suicide rate with increasing age in both sexes (Caribbean and Arabic countries), females only (South America and Central America) and males only (Eastern European countries and countries of the former Soviet Union). These unpublished findings were significantly different from the findings of the published study (Shah, 2007) where the stated exclusions were utilized.

This comparison illustrates how changes in the methodology in research on suicide rates can radically influence the findings. This is particularly important in cross-national research on suicide rates because of methodological issues. These include: data were not available for all the countries (Moscicki, 1995; Wasserman et al., 2005); the validity of these data was unclear (Diekstra, 1989; Wasserman et al., 2005); the legal criteria for the proof of suicide varies between countries and different regions within a country (Shah and Ganesvaran, 1994; Wasserman et al., 2005); some countries have poor death registration facilities (Shah and Ganesvaran, 1994); and cultural and religious factors and the stigma attached to suicide may lead to under-reporting of suicides (Abraham et al., 2005; Wasserman et al., 2005). It is important for researchers and readers carefully to consider the inclusion and exclusion groups in cross-national research on suicide rates before interpreting the findings because very different conclusions 
can be reached. Theoretically, there can only be certainty of any age-related trends in suicide rates if all the age-bands are utilized, even if the suicide rate is zero in some of the age-bands, because only this approach truly reflects all age groups.

\section{References}

Abraham, V. J., Abraham, S. and Jacob, K. S. (2005). Suicide in the elderly in Kanyambadi block, Tamil Nadu, South India. International fournal of Geriatric Psychiatry, 20, 953-955.

Adityanjee, D. R. (1986). Suicide attempts and suicide in India: cross-cultural aspects. International Fournal of Social Psychiatry, 32, 64-73.

Ajdacic-Gross, V., Bop, M., Gostynski, M., Lauber, C., Gutzwiller, F. and Rossler, W. (2006). Age-period-cohort analysis of Swiss suicide data, 1881-2000. European Archives of Psychiatry and Clinical Neurosciences, 256, 207-214.

Bhatia, S. C., Kahn, M. H. and Medirrata, R. P. (1987) High risk suicide factors across cultures. International fournal of Social Psychiatry, 33, 226-236.

Daradekh, T. K. (1989). Suicide in Jordan 1980-1985. Acta Psychiatrica Scandinavica, 79, 241-244.

Diekstra, R. F. W. (1989). Suicide and attempted suicide: an international perspective. Acta Psychiatrica Scandinavica, 80 (Suppl. 354), 1-24.

Mello-Santos, C., Bertolote, J. M. and Wang, Y. P. (2005). Epidemiology of suicide in Brazil (1980-2000): characterisation of age and gender rates of suicide. Revista Brasileira de Psiquiatria, 27, 131-134.

Moscicki, E. K. (1995). North American perspectives: epidemiology of suicide. International Psychogeriatrics, 7, 137-148.

Needleman, J., Mak, V. and Wessely, S. (1997). Suicide by age, ethnic group, coroner's verdict and country of birth: a three-year survey in inner London. British fournal of Psychiatry, 181, 463-467.

Raleigh, V. S., Bulusu, L. and Balarajan, R. (1990). Suicides among immigrants from the Indian subcontinent. British fournal of Psychiatry, 156, 46-50.

Sartorius, N. (1995). Recent changes in suicide rates in selected Eastern European and other European countries. International Psychogeriatrics, 7, 301-308.

Seiden, R. H. (1981). Mellowing with age: factors affecting the non-white suicide rate. International Fournal of Ageing and Human Development, 13, 265-284.

Shah, A. K. (2007). The relationship between suicide rates and age: an analysis of multinational data from the World Health Organization. International Psychogeriatrics, e-published ahead of print, DOI: $10.1017 /$ S1041610207005285.

Shah, A. K. and De, T. (1998). Suicide and the elderly. International fournal of Psychiatry in Clinical Practice, 2, 3-17.

Shah, A. K. and Ganesvaran, T. (1994). Suicide in the elderly. In E. Chiu and D. Ames (eds.), Functional Psychiatric Disorders of the Elderly (pp. 221-244). Cambridge: Cambridge University Press.

Skegg, K. and Cox, B. (1991). Suicide in New Zealand 1957-1986: influence of age, period and birth cohort. Australia and New Zealand Fournal of Psychiatry, 25, 181-190.

Snowdon, J. and Snowdon, D. (1995). Suicide in Australia. Paper presented at the 8th Congress of the International Psychogeriatric Association, Sydney, Australia.

Wasserman, D., Cheng, Q. and Jiang, G. X. (2005). Global suicide rates among young people aged 15-19. World Psychiatry, 4, 114-120. 
Woodbury, M. A., Manton, K. G. and Blazer, D. (1987). Trends in US suicide mortality rates 1968-1982: race and sex differences in age, period and cohort components. International fournal of Epidemiology, 17, 356-352.

Yip, P. S. F., Callanan, C. and Yuen, H. P. (2000). Urban/rural and gender differentials in suicide rates: East and West. Fournal of Affective Disorders, 57, 99-106.

\section{AjIT SHAH}

Professor of Ageing, Ethnicity and Mental Health, University of Central Lancashire, Preston, U.K. and Consultant Psychiatrist, West London Mental Health NHS Trust, London, U.K.

Email: ajit.shah@wlmht.nhs.uk 